\title{
Journal of Flood Risk Management
}

The Measurement of Current Changes in Land Levels as Input to Long Term Planning for Flood Risk Management Along the Thames Estuary

\begin{tabular}{|r|l|}
\hline Journal: & Journal of Flood Risk Management \\
\hline Manuscript ID: & draft \\
\hline Manuscript Type: & Original Manuscript \\
\hline $\begin{array}{r}\text { Date Submitted by the } \\
\text { Author: }\end{array}$ & $\mathrm{n} / \mathrm{a}$ \\
\hline Complete List of Authors: & $\begin{array}{l}\text { Bingley, Richard; University of Nottingham, IESSG } \\
\text { Williams, Simon; Proudman Oceanographic Laboratory } \\
\text { Press, Nigel; Nigel Press Associates Ltd } \\
\text { Aldiss, Don; British Geological Survey, Keyworth } \\
\text { Tarrant, Owen; Environment Agency, TE2100 Project }\end{array}$ \\
\hline Keywords: & Measurement, Land, Flood, Risk management \\
\hline
\end{tabular}




\title{
The Measurement of Current Changes in Land Levels as Input to Long Term Planning for Flood Risk Management Along the Thames Estuary
}

R. M. Bingley ${ }^{1}$, F. N. Teferle ${ }^{1}$, E J. Orliac ${ }^{1}$ A. H. Dodson ${ }^{1}$ S. D. P. Williams ${ }^{2}$ D. L. Blackman ${ }^{2}$ T. F. Baker ${ }^{2}$, M. Riedmann', M. Haynes ${ }^{3}$, N. Press ${ }^{3}$, D. T. Aldiss ${ }^{4}$, H. C. Burke ${ }^{4}$, B. C. Chacksfield $^{4}$, D. Tragheim ${ }^{4}$, O. Tarrant ${ }^{5}$, S. Tanner ${ }^{5}$, T. Reeder ${ }^{5}$, S. Lavery ${ }^{5}$, I. Meadowcroft ${ }^{6}$, S. Surendran $^{6}$, J. R. Goudie ${ }^{7}$ \& D. Richardson ${ }^{7}$

${ }^{1}$ Institute of Engineering Surveying and Space Geodesy (IESSG), University of Nottingham, UK;

${ }^{2}$ Proudman Oceanographic Laboratory (POL), Liverpool, UK; ${ }^{3}$ Nigel Press Associates Ltd. (NPA), Edenbridge, Kent, UK; ${ }^{4}$ British Geological Survey (BGS), Keyworth, Nottingham, UK; ${ }^{5}$ Environment Agency (EA) Thames Estuary 2100 Project, Charlton, London, UK; ${ }^{6}$ Environment Agency (EA), Reading UK; ${ }^{7}$ Department for Environment, Food and Rural Affairs (Defra), London, UK.

\section{Keywords}

Measurement; Land; Flood; Risk management.

\section{Correspondence}

R. M. Bingley, Institute of Engineering Surveying and Space Geodesy (IESSG), University of Nottingham, UK. E-mail richard.bingley@nottingham.ac.uk.

\begin{abstract}
Long term planning for flood risk management in coastal and estuarine areas requires timely and reliable information on changes in land and sea levels. In this paper we describe how we have produced a detailed, high resolution map of current changes in land levels for the Thames region, and carried out a new assessment of the changes in sea level relative to the land along the Thames Estuary over the past few decades / past century. We conclude the paper by considering the potential benefits of extended monitoring for the long term planning of flood and coastal defences in that region.
\end{abstract}

\section{Introduction}

Long term planning for flood risk management in coastal and estuarine areas requires timely and reliable information on changes in land and sea levels. Allowances for such changes are typically based on model estimates of future changes in global sea level, which have been available from the Intergovernmental Panel on Climate Change (IPCC) since 1990, and estimates of changes in land level from global or regional models based on geophysical or geological studies.

In Northern Europe, the dominant source of changes in land level is glacial isostatic adjustment (GIA), which means that the general pattern of expected changes in land level in Great Britain is one of uplift in Scotland and Northern England, subsidence on Shetland, and subsidence in Wales, Central and 
Southern England; or a North-South 'land tilt' of the order of millimetres per year. However, although GIA is the dominant source of changes in land level on a national scale, there are many other geological and engineering phenomena which can cause similar magnitudes of changes in land level over smaller regions and over varying time scales. The consequences of ignoring or not knowing the spatial and/or temporal variations of such changes in land level can have a significant impact on allowances made in long term planning for flood risk management.

Over the time period since the first two IPCC assessment reports in 1990 and 1995, monitoring techniques based on the use of artificial satellites or the measurement of gravity have been developed which have the potential to provide a 'direct measure' of current changes in land level. In this paper we show how three complementary monitoring techniques, namely the Global Positioning System (GPS), Absolute Gravimetry (AG) and Persistent Scatterer Interferometry (PSI), have been used in order to both obtain an estimate for an average change in sea level (decoupled from changes in land level) around the coast of Great Britain over the past few decades / past century and to produce a detailed, high resolution map of current changes in land levels for the Thames region. We will then show how a combination of these have been used to provide an assessment of the changes in sea level relative to the land along the Thames Estuary and present our conclusions, which have led to an improved understanding of the scale of rising sea levels in this region and are being used as a baseline from which to plan for managing flood risk over the next 100 years as part of the Environment Agency Thames Estuary 2100 project.

\section{Changes in land and sea levels around the coast of Great Britain}

Estimates of past changes in sea level relative to the land for a selection of tide gauges in the British Isles can be obtained from the Permanent Service for Mean Sea Level (PSMSL). When considering such estimates, it is clear that they vary between different regions of Great Britain and appear to be specific to individual tide gauges, as each value is affected by the changes in land level that have occurred at that tide gauge over the period of its measurements. If the variations in the values are simply due to sitespecific changes in land level, then by decoupling the changes in sea level from the changes in land level it should be possible to obtain a consistent value, which can be considered as the 'climate-related' component of changes in sea level around the coast of Great Britain. 
This is not a new idea, as Woodworth et al. (1999) used changes in land level based on the geological studies of (Shennan 1989) to obtain an estimate for an average change in sea level (decoupled from changes in land level) of the order of $1 \mathrm{~mm} / \mathrm{yr}$ around the coast of Great Britain over the past few decades / past century. GPS and AG, however, can provide a direct measure of the current change in land level at a tide gauge, which may be due to contributions from GIA along with other geological and engineering phenomena. When compared to estimates from geological studies, this has the obvious potential benefits that such measures are current, more specific to the tide gauge, and can be used in the future to isolate any spurious land level signals that could be misconstrued as accelerations in the climaterelated component of changes in sea level..

During the period from 1997 to 2001, we established continuous GPS (CGPS) stations at seven of the 44 tide gauges which form the national tide gauge network in Great Britain (Fig. 1). With the exception of Lerwick, which is approximately $5 \mathrm{~km}$ from the tide gauge and founded on solid rock, all of the other stations were established as close as possible to the tide gauge. From an analysis of daily GPS data for the period from March 1997 to December 2005 we obtained estimates of vertical station velocities. For more details on this, readers are referred to Teferle et al. $(2006,2007)$ and Bingley et al. (2007).

Over this same period, we also made near-annual, episodic AG measurements at three of the tide gauges which have CGPS stations, namely Newlyn, Aberdeen and Lerwick. In each case, AG stations were established which are housed inside a building, which will ideally remain in place and unchanged over a long period of time and is founded on solid rock. All of the measurements were obtained with an FG5 absolute gravimeter instrument owned by POL (Williams et al. 2001) and subject to analysis to obtain further estimates of vertical station velocities. For more details on this, readers are referred to Bingley et al. (2007).

Figs. $2 \mathrm{a}$ and $2 \mathrm{~b}$ show the negative of the 'emergence / subsidence (E/S) rate' based on 'AGaligned CGPS estimates of vertical station velocity' from two GPS solutions, plotted against the 'MSL trends' for the past few decades / past century based on PSMSL (2005). The figures are presented in this manner so as to give a positive correlation between the different parameters, and to be consistent with similar plots given in Woodworth et al. (1999). 
Just considering the vertical spread of the points, these figures graphically illustrate that, with the exception of Lerwick tide gauge on Shetland, the British tide gauges all show a rise in sea level over the past few decades / past century. Just considering the horizontal spread of the points, it can be commented that the changes in land level based on a combination of AG and CGPS are generally more negative than those from geophysical and geological studies; with the exception of the CGPS station at Newlyn, which has estimates of changes in land level which are less negative than that in Shennan \& Horton (2002).

The solid diagonal line in these figures would imply a zero average change in sea level (decoupled from changes in land level) around the coast of Great Britain over the past few decades / past century; whereas the dashed diagonal line would represent an average change of $1 \mathrm{~mm} / \mathrm{yr}$. Both figures clearly show that for Lerwick, the fall in sea level from the tide gauge measurements is not matched by an uplift in land level. In other words, this would seem to suggest that the Lerwick tide gauge measurements are an anomaly specific to this tide gauge; this is currently under further investigation. Excluding this tide gauge, our computed values for an average sea level rise (decoupled from changes in land level) are $0.9 \pm 0.2 \mathrm{~mm} / \mathrm{yr}$ and $1.1 \pm 0.3 \mathrm{~mm} / \mathrm{yr}$, based on Figs. $2 \mathrm{a}$ and $2 \mathrm{~b}$ respectively, i.e. a $1 \mathrm{~mm} / \mathrm{yr}$ rise as the climate related component of changes in sea level around the coast of Great Britain over the past few decades / past century.

\section{Changes in land levels in the Thames region}

In parallel to the research carried out on a national scale, we have used a combination of CGPS, episodic GPS (EGPS) and PSI on a regional scale, i.e. the Thames region. For this research we analysed CGPS and episodic GPS (EGPS) data from a network of 16 stations in the Thames region, within the framework that is provided by the national network of AG and CGPS stations, and we analysed synthetic aperture radar (SAR) data using PSI for hundreds of thousands of persistent scatterer (PS) points, to produce a detailed, high resolution map of current changes in land levels, and then interpreted the changes in land level based on various geoscience data sets.

When considering the changes in land level in the Thames region we are primarily trying to address the issue raised in the introduction in that although GIA is the dominant source of changes in land level on a national scale, there are many other geological and engineering phenomena which can cause similar magnitudes of changes in land level over smaller regions and over varying time scales. The drive 
behind using PSI was that it can provide good spatial coverage and refinement over a regional scale. One of the other great advantages of PSI is that, unlike GPS, where historical data availability is restricted to when a GPS receiver/antenna was deployed in the field, PSI can essentially 'go back in time', depending on the availability of suitable images from ERS-1, ERS-2 and ENVISAT satellites in the European Space Agency (ESA) archives. However, one of the restrictions of PSI is that it leads to relative rather than absolute movements; whereas GPS enables the measurement of changes in land level at a specific station, in a GPS reference frame (essentially a geometrical model of the Earth), and AG enables an independent measurement of changes in land level at a specific station, with reference to the centre of the Earth. Part of the objectives of the research work carried out, therefore, was to investigate how best to combine the information from these three complementary monitoring techniques.

\section{The use of PSI for monitoring changes in land levels}

Satellite-based SAR Interferometry (InSAR) is a method of using two or more SAR images, primarily for topographic mapping or digital elevation model generation. With further processing it is possible to allow the identification of surface changes through a technique known as Differential InSAR (DInSAR). PSI is a DInSAR technique that considers PS points, which relate to stable, reflective objects such as bare rock, buildings, bridges, lampposts etc., and make this technique ideal for monitoring in urban areas. PSI provides a measure of the movement of a PS point relative to a fixed PS point, termed the 'reference scatterer', in the direction from the PS point on the Earth's surface to the satellite (i.e. along the line-ofsight to the satellite).

For our study, the AOI was agreed as being approximately $95 \times 55 \mathrm{~km}$, centred on the Thames Estuary and encompassing the network of three CGPS and 13 EGPS stations which were established in the Thames region in 1997. Based on this AOI, all usable ERS SAR data from March 1997 to December 2005 and all usable ENVISAT ASAR data from December 2002 to December 2005 were subject to a PSI analysis, resulting in estimates of line-of-sight velocity for approximately 950,000 PS points.

\section{Combined GPS, AG and PSI estimates of changes in land levels for the Thames region}

To enable geological interpretations of any changes in land levels, we computed estimates of velocity for the dense network of PS points that were effectively estimates of changes in land level in the "combined 
GPS and AG reference frame', realised through the national component of our study. This was carried out in three stages: firstly a classification of the PS points close to each CGPS/EGPS station; followed by the calculation of a 'shift' to convert the line-of-sight velocities given with respect to the reference scatterer to 'AGGPS-aligned PSI estimates of vertical velocities' for the PS points; followed by the application of this shift to all 950,000 PS points in the database output from IPTA. For more details on this, readers are referred to (Bingley et al. 2007).

Fig. 3 presents the AGGPS-aligned PSI analysis map, where the location of the reference scatterer is marked by a white square and the monitoring network of CGPS and EGPS stations are marked as red circles. In this figure, each of the 950,000 PS points has been colour coded, depending on the vertical velocity of the point, on a scale of $+5 \mathrm{~mm} / \mathrm{yr}$ to $-5 \mathrm{~mm} / \mathrm{yr}$ ranging from blue, turquoise, green, yellow, red, where green is around zero. The overall picture is an average change in land level for the AOI of $-0.80 \mathrm{~mm} / \mathrm{yr}$ with a standard deviation of $\pm 0.89 \mathrm{~mm} / \mathrm{yr}$, with about $83 \%$ of all PS points having a negative value and $63 \%$ being between 0 to $-1.5 \mathrm{~mm} / \mathrm{yr}$ (shown by the predominance of yellow in Fig. 3). Apart from these there is: a concentration of turquoise (positive vertical velocities) to the West and North-West of the Thames region; concentrations of yellow/red (negative vertical velocities) along the River Thames and to the South of the River Thames in Central London; and a clear, linear feature in red (significantly more negative velocities) relating to subsidence around the Jubilee Line extension and the Battersea area.

\section{Geological interpretations based on the geoscience data sets}

The geological setting of the Thames region is described in Ellison et al. (2004). Considering this and the various processes that affect changes in land level in the Thames region, along with the spatial density of the PS points, specific geoscience data sets were used by BGS to enable the geological interpretation of any changes in land level. These data sets included: digital geological and geohazard maps; data on the thickness of Holocene deposits and of peat; regional groundwater level data; and geophysical data.

The geological interpretations were based on a comparison of the AGGPS-aligned PSI estimates of vertical velocity with the geoscience datasets, within a GIS. Clearly, to compare all 950,000 PS points individually was not feasible so an approach was adopted whereby the estimates were initially plotted by BGS in several ways within the GIS. These plots showed that the average changes in land level were far from being evenly distributed, with some areas having mainly undergone uplift, some areas having 
mainly undergone subsidence and some areas presenting a 'stippled effect' where PS points indicating uplift and subsidence were approximately balanced. In order to simplify the process of interpretation and also to help ensure that the data were interpreted in a reasonably consistent manner, a variety of these plots were inspected to identify 'domains' of approximately uniform changes in land level, and to note lineaments within the data distribution. This is analogous to processes employed in the geological interpretation of satellite images.

In this respect, although different plots tended to enhance different aspects of the distribution of changes in land level, a reasonably consistent pattern emerged and domain boundaries could be defined. Here it should be emphasised that the delineation/identification of the domains and lineaments was, except very locally, undertaken without reference to the geoscience datasets. In a few places, the domain boundaries were subsequently modified when considering some specific features at larger scales, but this was not done systematically. The resultant domains are shown in Fig. 4. As described, these domains were identified based on a qualitative, visual inspection of graphic data plots; however, once defined, they were substantiated by compiling statistics for each domain using the GIS.

As illustrated in Fig. 4, the domains of approximately uniform changes in land level were ranked from 1 to 6 , with individual areas within each rank given suffix letters to assist reference. Based on the figure, the following comments can be made:

- $\quad$ Domain 1 has probably experienced uplift, in general;

- $\quad$ Domains 4, 5 and 6 have experienced subsidence, in general;

- Domains 2 and 3 have, on the whole, also undergone subsidence, but these domains are of intermediate and mixed character, with some parts having undergone subsidence and some uplift.

Here it should be stated that these are general comments as, considering the uncertainties in the GPS, AG and PSI results, it is not really possible to make any conclusions regarding changes in land level of less than $0.5 \mathrm{~mm} / \mathrm{yr}$ magnitude. With this in mind, therefore, it is possible that Domain 1 could be uplifting more, while Domain 2 is slightly uplifting and Domain 3 is stable, or that Domain 1 could be stable or slightly subsiding while Domains 2 and 3 are definitely subsiding. However, there is some local geological evidence that implies that Domain 1 has indeed been rising, on average, over the past few hundred thousand years. 
From the comparisons between the geoscience data sets and the domain maps of uniform average changes in land level it was specifically concluded that:

- $\quad$ regional patterns of uplift and subsidence are controlled, to some extent, by deep-seated geological structures;

- $\quad$ parts of the AOI, north-west of the Wimbledon Fault and its lateral extensions (Domains 1, 2 and 3), are prone to uplift or relatively slight subsidence centred on a gravity 'high' within the geological structure known as the 'Midlands Microcraton';

- the remainder of the AOI (Domains 4, 5 and 6) is prone to subsidence;

- where Holocene deposits are extensive and thicker than about 5m (Domains 5C, 5F, 6D and $6 \mathrm{E}$ ), the ground is generally prone to a greater rate of subsidence than found regionally;

- groundwater abstraction (Domain 5A) and tunnelling (Domain 6A, 6B and 6C) can cause subsidence at a similar rate to that found within areas of Holocene deposits, and for Domain 5A, there is also some local control by neotectonic movement on near-surface structures, such as the Wimbledon Fault.

Overall, it was concluded that the main sources of significant current changes in land level for the Thames region are: regional uplift (in the west) and regional subsidence (especially in the north-east and south-east), groundwater abstraction and compaction of Holocene deposits.

\section{Changes in land and sea levels along the Thames Estuary}

Considering our combined GPS, AG and PSI estimates of changes in land level for the Thames region along with our estimates for the average change in sea level (decoupled from changes in land level) around the Coast of Great Britain over the past few decades / past century, the overall effect is a 1.8 to $3.2 \mathrm{~mm} / \mathrm{yr}$ rise in sea level with respect to the land along the Thames Estuary over the past few decades / past century. The lower figure in this range is based on a combination of a $0.9 \mathrm{~mm} / \mathrm{yr}$ sea level rise, as the low estimate from our study, and a $0.9 \mathrm{~mm} / \mathrm{yr}$ subsidence for Domains $4 \mathrm{E}$ and $4 \mathrm{H}$; whereas, the higher figure in this range is based on a combination of a $1.1 \mathrm{~mm} / \mathrm{yr}$ sea level rise, as the high estimate from our study, and a $2.1 \mathrm{~mm} / \mathrm{yr}$ subsidence for Domains $6 \mathrm{D}$ and $6 \mathrm{E}$. The direct measure of change in sea level with respect to the land provided by Sheerness tide gauge is about $+1.6 \mathrm{~mm} / \mathrm{yr}$, based on PSMSL (2005). 
This is slightly below the lower bound of our 1.8 to $3.2 \mathrm{~mm} / \mathrm{yr}$ range; however, as part of our research, we carried out a separate analysis using the tide gauge data for Sheerness from only the last five decades and obtained a value of $+2.0 \mathrm{~mm} / \mathrm{yr}$, which is clearly within that range.

Our estimates for the change in sea level (decoupled from changes in land level) around the Coast of Great Britain over the past few decades / past century compare well with that presented by Woodworth et al. (1999), i.e. of the order of $1 \mathrm{~mm} / \mathrm{yr}$, but both ours and their estimates were based on all available sea level data for each particular tide gauge considered. In comparison, the most recent IPCC report considered evidence from combined tide gauge and satellite altimetry measurements and concluded that globally averaged sea level had risen by $1.8 \pm 0.5 \mathrm{~mm} / \mathrm{yr}$ over the specific period of 1961 to 2003 , and commented that numerous papers on satellite altimetry results showed a rise of $3.1 \pm 0.7 \mathrm{~mm} / \mathrm{yr}$ over the period of 1993 to 2003 (IPCC 2007).

Substituting these global averages for our average value for the climate related component of changes in sea level would result in an assessment of the combined effect of changes in land and sea levels of a 2.7 to $3.9 \mathrm{~mm} / \mathrm{yr}(1.8+0.9$ to $1.8+2.1 \mathrm{~mm} / \mathrm{yr})$ rise in sea level with respect to the land along the Thames Estuary over the last four decades or a 4.0 to $5.2 \mathrm{~mm} / \mathrm{yr}(3.1+0.9$ to $3.1+2.1 \mathrm{~mm} / \mathrm{yr})$ rise over the last decade. However, the use of such globally averaged values for past changes in sea level is clearly not as relevant to flood risk management along the Thames Estuary as the use of a specific value for the average change in sea level around the coast of Great Britain.

Using our specific value of $0.9 \mathrm{~mm} / \mathrm{yr}$ over the past few decades / past century, highlights the contribution of the measured changes in land level to the rise in sea level with respect to the land, i.e. the land level contribution has the effect of amplifying the impact of the climate related component of changes in sea level by up to $333 \%$ (as $(0.9+2.1) / 0.9 * 100 \%$ ). It could be argued that this value is slightly exaggerated as it is based on comparison with a scenario of assuming no changes in land level at all along the Thames Estuary. Prior to our study, the adopted value for changes in land level for London was $0.8 \mathrm{~mm} / \mathrm{yr}$ subsidence, based on the geological studies of Shennan \& Horton (2002). Clearly our values of between 0.9 and $2.1 \mathrm{~mm} / \mathrm{yr}$ subsidence for the land along the Thames Estuary are significantly greater than this value by up to 2.5 times and even if the $0.8 \mathrm{~mm} / \mathrm{yr}$ subsidence was used as the baseline for comparisons, it would still mean that our estimates for the land level contribution would have the effect of 
amplifying the impact of the climate related component of changes in sea level by up to $176 \%$ (as $(0.9+2.1) /(0.9+0.8) * 100 \%)$.

\section{Conclusions}

As stated in the introduction, long term planning for flood risk management in coastal and estuarine areas requires timely and reliable information on changes in land and sea levels. In this paper we have described how, by using AG, GPS and PSI, we have produced a detailed, high resolution map of current changes in land levels for the Thames region, and carried out a new assessment of the changes in sea level relative to the land along the Thames Estuary over the past few decades / past century. From our measurements, we have obtained: new estimates of current changes in land level for the Thames region which range from approximately $0.3 \mathrm{~mm} / \mathrm{yr}$ uplift to $2.1 \mathrm{~mm} / \mathrm{yr}$ subsidence and correlate with certain aspects of geoscience data sets to explain the pattern of land movements observed on a regional scale; a new estimate for the combined effect of changes in land and sea levels as a 1.8 to $3.2 \mathrm{~mm} / \mathrm{yr}$ rise in sea level relative to the land along the Thames Estuary over the past few decades / past century.

Prior to our study, the adopted value for changes in land level for London was $0.8 \mathrm{~mm} / \mathrm{yr}$ subsidence, based on the geological studies of Shennan \& Horton (2002). Clearly our values of between 0.9 and $2.1 \mathrm{~mm} / \mathrm{yr}$ subsidence for the land along the Thames Estuary are significantly greater than this value by up to 2.5 times and mean that our estimates for the land level contribution have the effect of amplifying the impact of the climate related component of changes in sea level by up to $176 \%$.

In terms of the long term planning of flood and coastal defences in the Thames Region, the results obtained have demonstrated that long term changes in land and sea levels can be monitored by using a combination of three complementary monitoring techniques: CGPS and AG on a national scale and CGPS/EGPS and PSI on a regional and local scale. Extended monitoring of changes in land and sea levels around the coast of Great Britain would lead to increasingly concurrent sea level and land level data and for estimates of any accelerations in changing sea level to be made. This will enable the validation of climate change model predictions of sea level rise around Great Britain, particularly as we move into the period of increasing variance between the different IPCC scenario predictions, which will lead to a better assessment of risk and more informed decisions on planning and managing flood risk at the coast and in our estuaries. Coupled with extended monitoring of changes in land levels along the 
Thames Estuary this could then form the basis of an adaptive strategy for the long term planning of flood and coastal defences in that region.

\section{Acknowledgements}

The research detailed in this paper was funded by the Department for Environment, Food and Rural

Affairs (Defra) and the Environment Agency (EA) in the UK through the Thames Estuary 2100 project.

A full, formal scientific report on the research detailed in this paper has been published as R\&D Technical

Report FD2319/TR (Bingley et al. 2007) and may be downloaded from the Defra/EA Joint R\&D FCERM

Programme website in the UK (www.defra.gov.uk/environ/fcd/research). We would like to acknowledge

the data and products provided by IGS, the services of the NERC British Isles GPS archive

Facility(BIGF) and the PSMSL. Don Aldiss, Helen Burke, Barrie Chacksfield and Doug Tragheim

publish with the permission of the Executive Director, British Geological Survey (NERC). The views

expressed in this article are those of the authors and do not represent the views of either Defra or EA.

\section{References}

Bingley, R. M., Teferle, F. N., Orliac, E. J., Dodson, A. H., Williams, S. D. P., Blackman, D. L., Baker, T. F., Riedmann, M., Haynes, M., Aldiss, D. T., Burke, H. C., Chacksfield, B. C. and Tragheim, D. (2007) Absolute fixing of tide gauge benchmarks and land levels: measuring changes in land and sea levels around the coast of Great Britain and along the Thames Estuary using GPS, absolute gravimetry, persistent scatterer interferometry and tide gauges. Defra/EA Joint R\&D FCERM Programme R\&D Technical Report FD2319/TR, April 2007.

Ellison, R. A., Woods, M. A., Allen, D. J., Forster, A., Pharaoh, T. C. and King, C. (2004) Geology of London. Memoir of the British Geological Survey, Sheets256 (North London), 257 (Romford), 270 (South London) and 271 (Dartford), England and Wales.

IPCC (2007) Climate Change 2007: The Physical Science Basis. Contribution of Working Group I to the Fourth Assessment Report of the Intergovernmental Panel on Climate Change (Solomon, S., Qin, D., Manning, M., Chen, Z., Marquis, M., Avery, K. B., Tignor, M., Miller, H. L., eds). Cambridge University Press, Cambridge, United Kingdom and New York, NY, USA, 996 pp.

PSMSL (2005) Table of MSL secular trends derived from Permanent Service for Mean Sea Level (PSMSL) RLR data. http://www.pol.ac.uk/ psmsl/datainfo/rlr.trends [update of 3 August 2005]

Shennan, I. (1989) Holocene crustal movements and sea-level changes in Great Britain. Journal of Quaternary Science, 4(1), 77-89.

Shennan, I. and Horton, B. (2002) Holocene land-and sea-level changes in Great Britain. Journal of Quaternary Science, 17(5-6), 511-526.

Teferle, F. N., Bingley, R. M., Williams, S. D. P., Baker, T. F. and Dodson, A. H. (2006) Using continuous GPS and absolute gravity to separate vertical land movements and changes in sea level at tide gauges in the UK. Philosophical Transactions of the Royal Society Series A: Mathematical, Physical, and Engineering Sciences, 364, 10.1098/rsta.2006.1746, 971-930.

Teferle, F. N., Orliac, E. J. and Bingley, R. M (2007) An assessment of Bernese GPS software precise point positioning using IGS final products for global site velocities. GPS solutions, 10.10007/s10291006-0051-7.

Williams, S. D. P., Baker, T. F. and Jeffries, G. (2001) Absolute gravity measurements at UK tide gauges. Geophysical Research Letters, 28(12), 2317-2320. 
Woodworth, P. L., Tsimplis, M. N., Flather, R. A. and Shennan, I. (1999) A review of the trends observed in British Isles mean sea level data measured by tide gauges. Geophysical Journal International, 136, 651-670. 


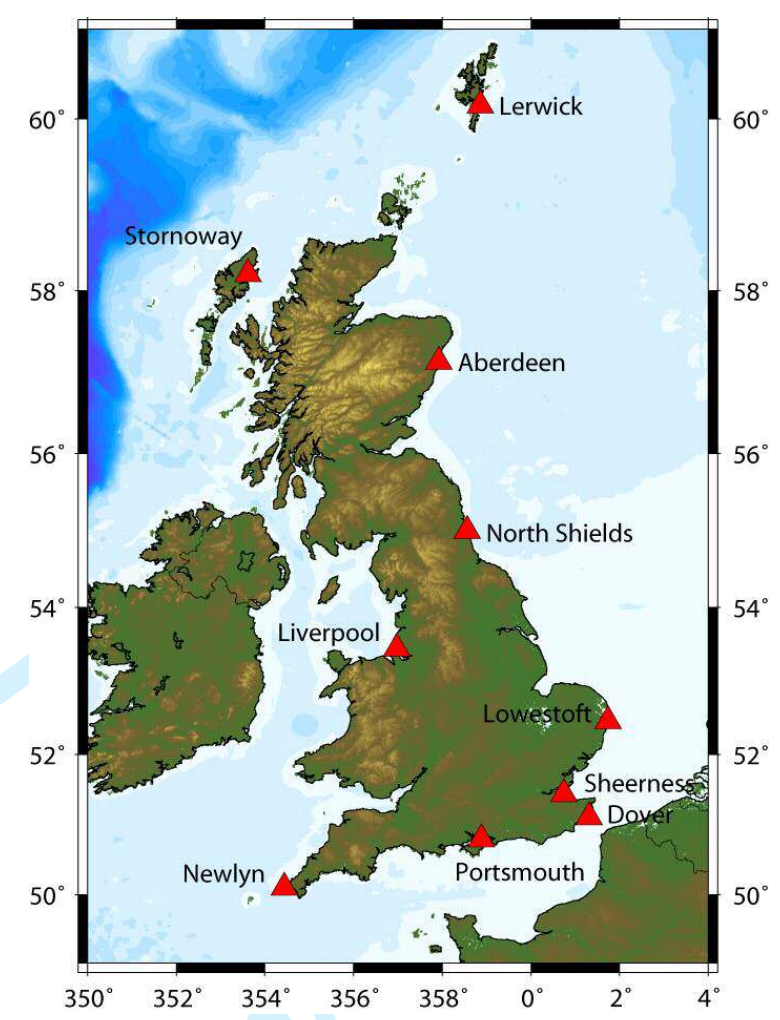

Fig. 1. Map showing the location of the seven stations established at or close to tide gauges in Great Britain. 

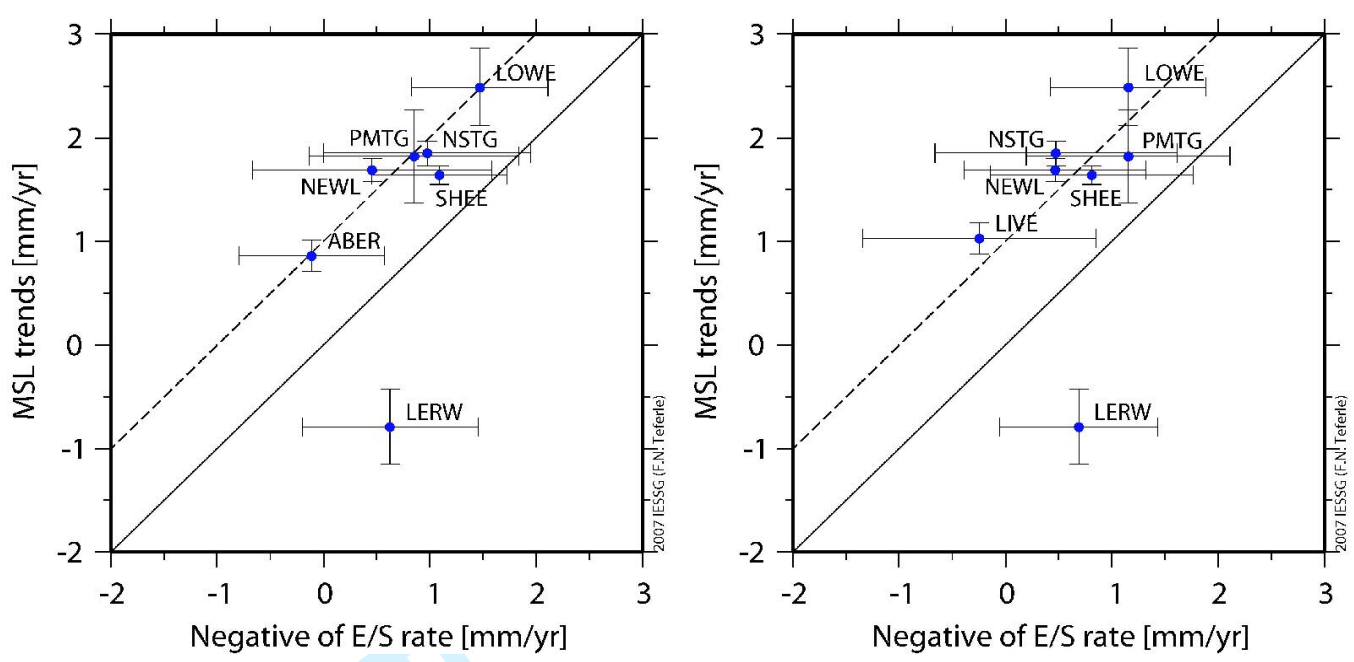

Fig. 2. Relative MSL trends for seven tide gauges compared with the negative of the emergence/submergence (E/S) rates based on a combination of $A G$ and two GPS solutions. In this figure, LERW is Lerwick, ABER is Aberdeen, NSTG is North Shields, LIVE is Liverpool, LOWE is Lowestoft, SHEE is Sheerness, PMTG is Portsmouth and NEWL is Newlyn. 


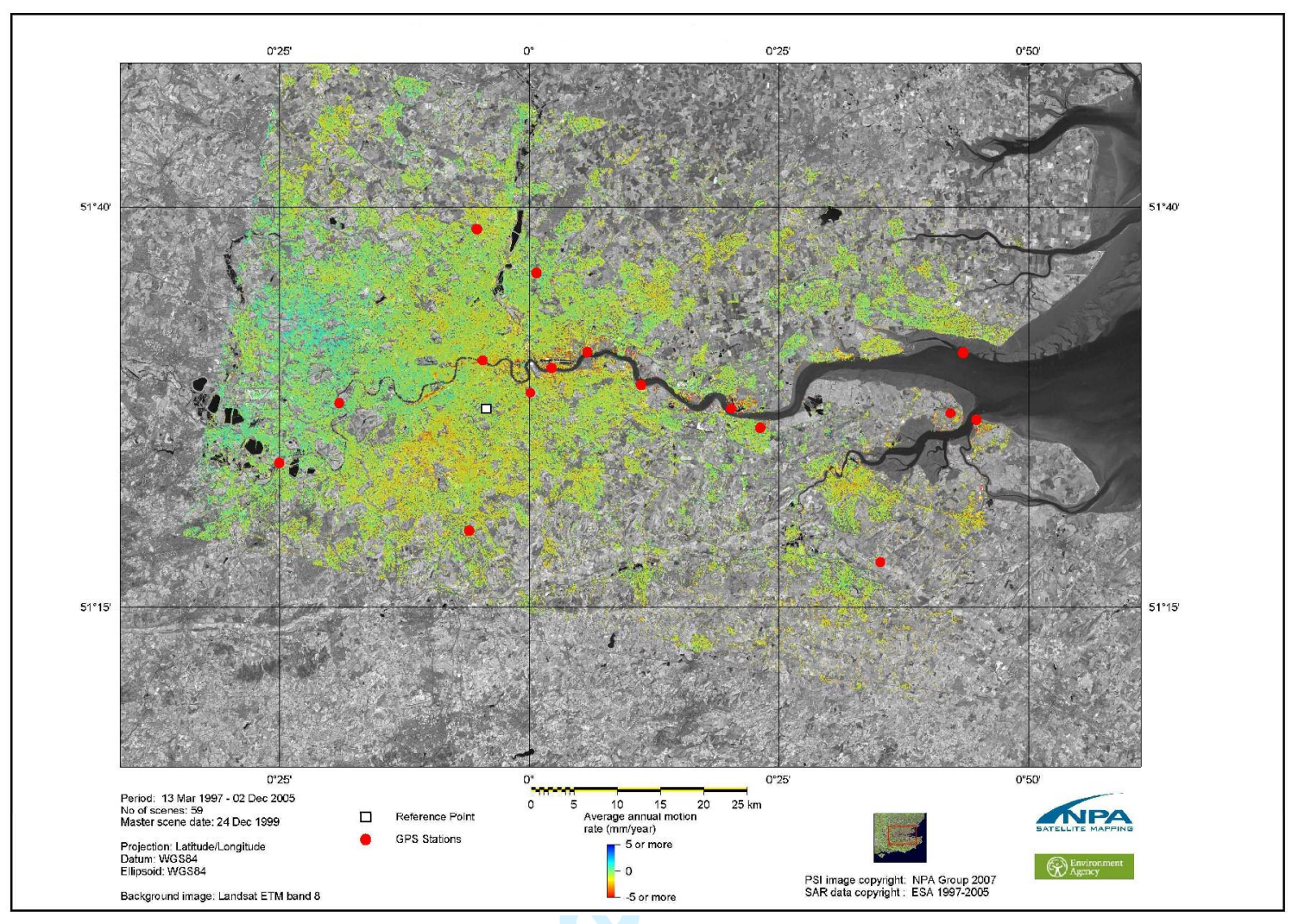

Fig. 3. AGGPS-aligned PSI analysis map for the 950,000 PS points in the Thames region. 


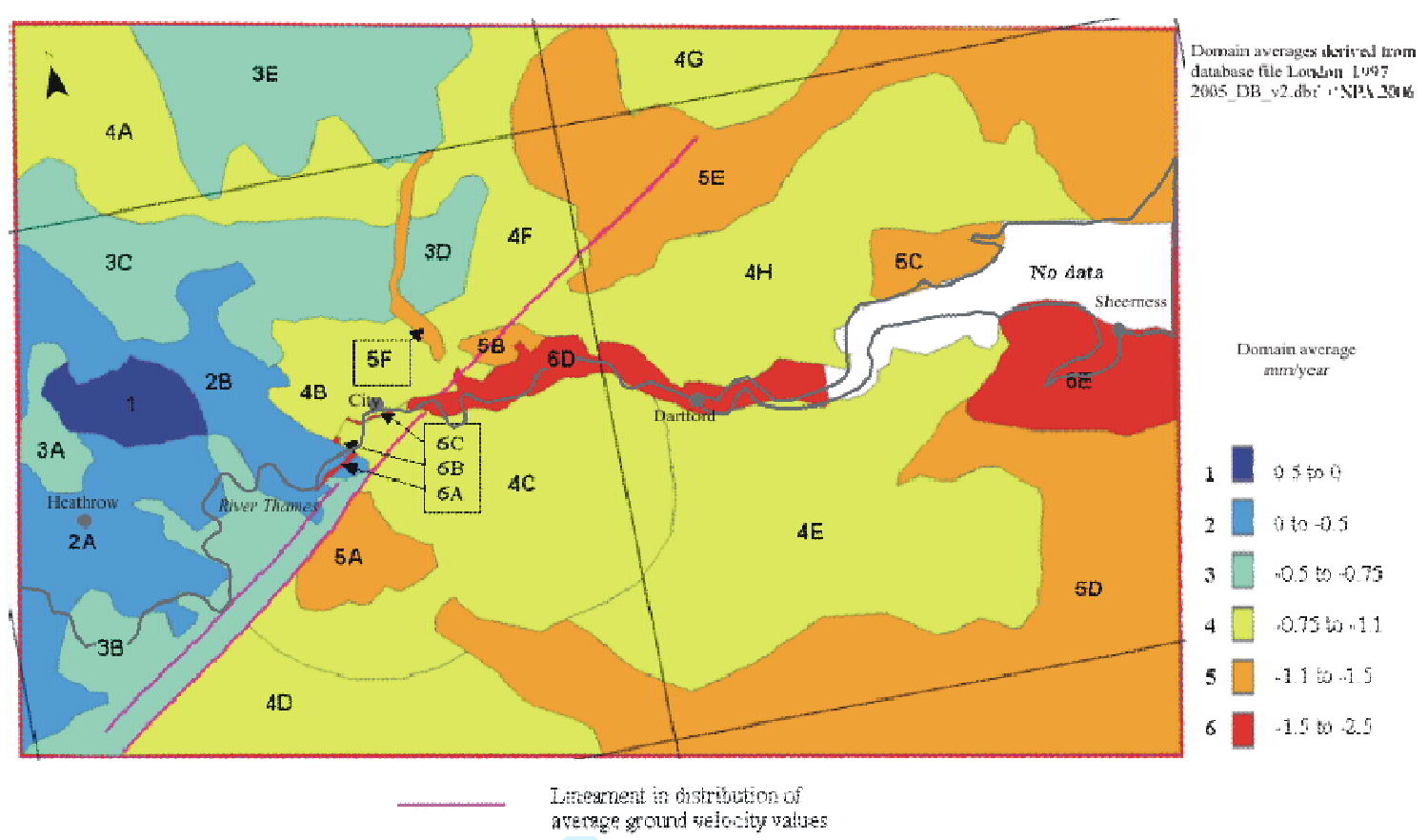

Fig. 4. Domains of approximately uniform changes in land level identified for the Thames region. 
1
2
3
4
5 $\quad$ Word count $=4994$ words 